University of Nebraska - Lincoln

DigitalCommons@University of Nebraska - Lincoln

Faculty Publications, Department of Psychology

Psychology, Department of

$2-1-2006$

\title{
Weekly Problems Scales: Instruments for Sexually Abused Youth and Their Nonoffending Parents in Treatment
}

\author{
Genelle K. Sawyer \\ University of Nebraska-Lincoln, genelle.sawyer@citadel.edu \\ Eugenia Hsu Tsao \\ University of Nebraska-Lincoln \\ David J. Hansen \\ Univertsity of Nebraska-Lincoln, dhansen1@unl.edu \\ Mary Fran Flood \\ University of Nebraska-Lincoln, mflood2@unl.edu
}

Follow this and additional works at: https://digitalcommons.unl.edu/psychfacpub

Part of the Psychiatry and Psychology Commons

Sawyer, Genelle K.; Tsao, Eugenia Hsu; Hansen, David J.; and Flood, Mary Fran, "Weekly Problems Scales: Instruments for Sexually Abused Youth and Their Nonoffending Parents in Treatment" (2006). Faculty Publications, Department of Psychology. 7.

https://digitalcommons.unl.edu/psychfacpub/7

This Article is brought to you for free and open access by the Psychology, Department of at DigitalCommons@University of Nebraska - Lincoln. It has been accepted for inclusion in Faculty Publications, Department of Psychology by an authorized administrator of DigitalCommons@University of Nebraska - Lincoln. 


\title{
Weekly Problems Scales: Instruments for Sexually Abused Youth and Their Nonoffending Parents in Treatment
}

\author{
Genelle K. Sawyer \\ Eugenia Hsu Tsao \\ David J. Hansen \\ Mary Fran Flood \\ University of Nebraska-Lincoln
}

This study's purpose was to determine if efficient measures could be created to assess multiple problematic behaviors identified in youth who were sexually abused and in treatment. Because of the lack of easily administered brief instruments that assess multiple domains of interest in this population, complementary parent and child assessment measures were developed. The Weekly Problems Scale-Child Version (WPS-C) and the Weekly Problems Scale-Parent Version (WPS-P) were created to monitor the weekly progress of the child and family in treatment and focus specifically on common areas of difficulties in this population. Exploratory factor analysis was conducted to assist in identifying the number of underlying dimensions in the scales. Results indicate that the WPS-C and WPS-P demonstrate adequate internal consistency, temporal stability, and construct validity. The WPS-C and WPS-P display significant promise as research and clinical assessment tools for use with youth who are sexually abused and their nonoffending parents in treatment.

Keywords: child sexual abuse; assessment; treatment; psychometrics

Child sexual abuse (CSA) continues to be a pervasive and well-documented problem. Child protective service agencies in the United States reported that in 20011.2 children per 1,000 experienced sexual abuse (U.S. De- partment of Health and Human Services, 2003). The impact of CSA has received widespread attention by researchers in recent decades. Multiple studies have delineated the short-term and long-term consequences of CSA, which include depression, anxiety, poor self-esteem, substance abuse, self-harm behavior, posttraumatic stress symptoms, sexual behavior problems, cognitive distortions, attribution errors, and disturbed relatedness (e.g., Briere \& Runtz, 1993; Kendall-Tackett, Williams, \& Finkelhor, 1993; Paolucci, Genuis, \& Violato, 2001; Valle \& Silovsky, 2002). Although the list of potential outcomes of CSA is lengthy, a systematic review of the literature on consequences of CSA revealed three critical target areas affected by sexual abuse: the individual or "self" (e.g., self-esteem, internalizing feelings), relationships (e.g., social interactions, externalizing problems with family and peers), and sex (e.g., sexual knowledge, sexual abuse-specific issues; Futa, Hecht, \& Hansen, 1996; Hansen, Hecht,\& Futa, 1998). However, a long-standing finding of sexual abuse research is the lack of a unified clinical presentation or pattern of post-sexual abuse problems experienced by the majority of the victims.

Because of the diverse clinical presentation of youth following disclosure of CSA, most experts suggest that children's psychological functioning be assessed using several different measures and methods. Specifically, it is important to measure global adjustment and

Published in Child Maltreatment 11:1 (February 2006), pp. 34-48.

DOI : $10.1177 / 1077559505283550$ (c) 2006 Sage Publications. Used by permission. 
general distress (e.g., internalizing and externalizing problems) and abuse-specific concerns (e.g., posttraumatic stress symptoms, sexual problems; Briere, 1996; Wolfe \& Birt, 1995). In addition, adequacies of family functioning and interpersonal relationship have been highlighted as major variables relating to improvement in children who are sexually abused (e.g., Oates, O'Toole, Lynch, Stern, \& Cooney, 1994). A review of the literature reveals that assessment of the more global issues experienced by children who are sexually abused has relied heavily on the use of the Child Behavior Checklist (CBCL; Achenbach, 1991) and the Children's Depression Inventory (CDI; Kovacs, 1992) and various measures of anxiety, including the State-Trait Anxiety Inventory for Children (STAIC; Spielberger, 1973) and the Revised Children's Manifest Anxiety Scale (R-CMAS; Reynolds \& Richmond, 1985). In addition, several measures have been developed in recent decades to specifically address sexual abuse-related symptoms. A sample of these include the Fear Survey Schedule for Children-Revised (FSSC-R; Ollendick, 1983), the Children's Impact of Traumatic Events-Revised (CITES-R; Wolfe, Gentile, Michienzi, Sas, \& Wolfe, 1991), the Child Sexual Behavior Inventory2nd version (CSBI-2; Friedrich et al., 1992), the Children's Attributions and Perceptions Scale (Mannarino, Cohen, \& Berman, 1994), and the Trauma Symptom Checklist for Children (TSCC; Briere, 1995).

Regardless of the targeted area of functioning, it is critical that psychometrically sound instruments are utilized in these assessments. In addition, assessments for youth who are sexually abused and their families need to be multidimensional using multiple informants. However, a major challenge in conducting comprehensive assessments is the time required to complete them, particularly when attempting to track changes during the course of treatment. Thus far, the majority of outcome studies have relied on comprehensive assessments conducted at pretreatment and posttreatment (e.g., Cohen \& Mannarino, 1996a, 1998; Deblinger, Stauffer, \& Steer, 2001; McGain \& McKinzey, 1995; Monck, 1997). However, research has indicated that the use of pretreatment and posttreatment assessment as the sole means of collecting data should be avoided. According to Lambert and Hawkins (2004), more frequent assessment should be conducted for at least two reasons: (a) the end of treatment is rarely planned because of dropout and, therefore, many clients do not complete the post-treatment assessment and (b) many clients make the most significant change at the beginning of treatment, and this is not assessed in the preassessment and/or postassessment format. Therefore, Lambert and
Hawkins recommend that "patients complete a measure of psychological status prior to each session” (p. 497).

The lack of more frequent assessments is likely because of the difficulty and inefficiency of conducting the multiple measures with more regularity, while attempting to simultaneously complete treatment. In addition, many of the commonly used assessment measures are not specifically designed for frequent use or monitoring of symptom change in a short time period. For instance, the CBCL asks the rater to rate the child's behavior during the past 6 months, making the use of norms for measurement of weekly change difficult. Directions for the CSBI-2 utilize a similar 6-month referent period. Although some measures utilize a shorter referent period and are more efficient for frequent use (i.e., the CDI), they focus on specific consequences of the sexual abuse and do not assist in the measurement of multiple domains of functioning.

To date, very few brief, global assessment instruments have been designed for frequent use with children in general, let alone children who are sexually abused. A comprehensive search of the literature revealed the existence of only one general measure and two such measures specific to children who are sexually abused. The Youth Outcome Questionnaire (YOQ; Burlingame, Wells, \& Lambert, 1996), the child-adolescent version of the Outcome Questionnaire (OQ-45.2; Lambert et al., 1996), is a 45-item parent report measure constructed specifically to track treatment progress in youth. The YOQ yields six subscales: Intrapersonal Distress, Somatic, Interpersonal Relations, Social Problems, Behavioral Dysfunction, and Critical Items. Although this measure has proven useful with a general psychiatric sample, it relies solely on parent report, includes more items than may be practical for weekly use in some clinical situations, and assesses a wider breadth of symptoms that might not require weekly monitoring across a majority of youth (e.g., eating problems, thought disorder). More specific to sexual abuse, the Weekly Behavior Report (WBR; Cohen \& Mannarino, 1993, 1996b) is designed to document the frequency of 21 specific problematic behaviors (e.g., sleep difficulties, anxiety symptoms, sexual behavior, aggressive and oppositional behaviors) associated with sexual abuse during the course of a week. Parents are asked to record specific behaviors on a daily basis, allowing for an exact measure of the frequency of these behaviors. However, the WBR is specifically designed for use with preschoolage children, and many of the assessed behaviors are not relevant for school-aged or adolescent youth. The second child sexual abuse-specific measure, the Child Report of Treatment Issue Resolution (CRTIR; Nelson- 
Gardell, 1997), is a 63-item measure designed to be a rapid self-report instrument for youth who are sexually abused and in treatment. With a sample of females who were sexually abused (ages 10 to 17 years), the CRTIR yielded four subscales: Self-Protection, Stigma/Shame/ Fear, Social Buffering, and Self-Blame. Although designed to be a brief assessment measure, the CRTIR continues to be lengthy with 63 items and would be difficult to complete with efficiency on a weekly basis. In addition, neither the WBR nor the CRTIR were designed for use with the child and a caregiver, and neither adequately cover the three critical target areas (i.e., the individual or "self," relationships, and sex) specified in the literature.

The primary purpose of the current study was to determine if efficient parent and child measures could be created to assess multiple problematic behaviors identified in youth who were sexually abused and in treatment. Because of the lack of easily administered brief instruments that assess multiple domains of interest in this population, the Weekly Problems Scale-Child Version (WPS-C) and the Weekly Problems ScaleParent Version (WPS-P) were developed for use as an initial assessment and as a repeated measure in treatment of the functioning of youths who were sexually abused (Futa, Hecht, Sawyer, \& Hansen, 2004). The WPS-C and the WPS-P were developed from a review of existing literature to monitor the weekly progress of the child and family in treatment and created to assess the three critical target areas impacted by sexual abuse (i.e., the individual or "self," relationships, and sex). Thus, the scale items focus specifically on common areas of difficulties in this population: negative mood, problem behavior, problem interactions with others, and abuse-related emotional and communication problems. A variety of psychometric analyses were conducted to address the following: scale identification, internal consistency, temporal stability, and construct validity.

\section{METHOD}

\section{Participants}

Participants were 64 children and adolescents who were sexually abused (ages 6.75 years to 16.75 years) and 64 of their parents who are nonoffending who were seeking cognitive-behavioral group treatment at an outpatient clinic. Families were recruited by contacting appropriate agencies in the community about Project SAFE (Sexual Abuse Family Education) and mailing brochures to provide information about the treatment. Community agencies included a children's advocacy center in Nebraska, the Nebraska Department of Health and Human Services, and professionals who treat children and adolescents who were sexually abused.

Parents who were nonoffending in the sample had a mean age of 36.11 years $(S D=6.04)$ with a range of 23 years to 48 years. Forty eight $(75 \%)$ of the parents were the biological mother of the child, and 8 (12.5\%) were the biological father; remaining caregivers included stepmother, adoptive mother, aunt, uncle, and foster mother. The majority of parents were White (92.2\%), while $3.1 \%$ were African American, $1.6 \%$ were $\mathrm{La}^{-}$ tino American, and 3.1\% were biracial. Twenty-nine (45.3\%) parents who were nonoffending were married, 20 (31.3\%) were divorced, 8 (12.5\%) were separated, 6 (9.4\%) were never married but living with someone, and 1 parent's (1.6\%) status was unknown. Regarding education level, $11(17.2 \%)$ of the parents did not graduate from high school, 19 (29.7\%) were high school graduates, $19(29.7 \%)$ completed some college, 7 (10.9\%) had an associates degree, 7 (10.9\%) had a bachelor's degree, and $1(1.6 \%)$ had a master's degree. Of the 64 parents, $73.4 \%$ were currently employed. Parents were distributed across income brackets (per annum) in the following pattern: U.S. $\$ 15,000$ or less, $32.8 \%$; $\$ 15,001$ to $\$ 25,000,15.6 \%$; $\$ 25,001$ to $\$ 40,000,25.0 \%$; $\$ 40,001$ to $\$ 60,000,10.9 \%$; $\$ 60,001$ to $\$ 100,000,12.5 \%$; more than $\$ 100,001,1.6 \%$; unknown, $1.6 \%$.

The children who completed assessments ranged in age from 6 years 9 months to 16 years 9 months old with a mean age of 12 years $(S D=2.6)$. The sample included 35 (54.7\%) school-age children (ages 7 to 12 years), and 29 (45.3\%) adolescents (ages 13 to 17 years). One of the adolescents was not attending school but participated in evening courses to obtain her high school equivalency degree. Fifty one (79.7\%) were girls, and 13 (20.3\%) were boys. Regarding ethnic identity, 54 (84.4\%) victims were White, 2 (3.1\%) were Latino American, 1 (1.6\%) was African American, 5 (7.8\%) were biracial, and 2 (3.1\%) were of mixed race.

Families were selected for study participation using the following criteria: (a) the child was between age 7 and 16 years, (b) the parent who was nonoffending assumed a care-giving role within the family (e.g., stepparents, foster parents, grandparents), and (c) the sexual abuse allegation was investigated by protective services. No restrictions were applied to the relationship between the victim and alleged perpetrator (i.e., intrafamilial vs. extrafamilial) or to the gender of the victim, parent who was nonoffending, or the perpetrator. The single exclusionary criterion was significantly impaired cognitive and/or intellectual functioning of the child 
or parent, and only one child was excluded from the present study because of impaired cognitive functioning.

\section{Child Measures}

Child participants in the current study were administered the following instruments under the supervision of a clinical psychology graduate student (listed in alphabetical order):

Children's Depression Inventory (CDI). The CDI (Kovacs, 1992) is a 27 -item self-report measure that assesses depression in children ages 7 to 17 years. One child in the study was 6 years 9 months at the time of the pretreatment assessment. However, because of the minimal age discrepancy (3 months), the supervision of a graduate student throughout the assessment, and the child's intellectual functioning, it was clinically determined that the child was capable of understanding and answering the questionnaire. Children are asked to endorse statements reflecting the cognitive and somatic symptoms of depression as they relate to themselves. Respondents are instructed to rate how they felt in the past 2 weeks based on three choices that are keyed from 0 to 2 with the higher scores indicating higher symptom severity. This measure has been found to be reliable with adequate internal consistency ranging from .71 to .89. Test-retest reliability has also been established (.72 to .84$)$. $T$-score norms are available for boys and girls separately ages 7 to 12 years and ages 13 to 17 years.

Children's Fears Related to Victimization (CFRV). The CFRV is a 27-item subscale of the Fear Survey Schedule for Children-Revised (FSSC-R; Ollendick, 1983) and was previously known as the Sexual Abuse Fear Evaluation or SAFE (Wolfe \& Wolfe, 1986). The CFRV was originally designed for children ages 7 to 12 years; however, it has been used in research with youth up to age 16 years (e.g., Burkhardt, Loxton, \& Muris, 2003; Ollendick, Langley, \& Jones, 2001; Westenberg, Drewes, \& Goedhart, 2004). The CFRV lists situations that children who are sexually abused seem to find distressing (e.g., people not believing me). Using a 3-point scale, children rate from none to a lot how upsetting they find each situation. Initial psychometric data are available on the SAFE revealing two subscales (labeled as Sex-Associated Fears and Interpersonal Discomfort) with alphas of .81 and .80, respectively (Wolfe, Gentile, \& Klink, 1988; Wolfe, Gentile, \& Wolfe, 1989).

Children's Impact of Traumatic Events-Revised (CITES-R). The CITES-R (Wolfe et al., 1991) is a structured interview for use with children between ages 8 and 16 years. Five children fell below the age 8 cutoff; however, because of the structured interview format of the questionnaire it was clinically determined that all children were capable of understanding and answering the questions. The CITES-R measures the impact of sexual abuse from the child's perspective (i.e., thoughts and feelings about what happened to them) using four main scales: Posttraumatic Stress, Abuse Attributions, Social Reactions, and Eroticism. Moderate support has been demonstrated for the psychometric properties of the CITES-R (Chaffin \& Shultz, 1999). Specifically, the four main scales performed well whereas other subscales demonstrated more variability. The instrument's temporal stability was found to be low; however, Chaffin and Shultz (1999) question whether this finding may reflect the lack of stability in sexual abuse-related characteristics (e.g., symptoms, attributions, or perceptions) rather than CITES-R's unreliability over time.

Children's Loneliness Questionnaire (CLQ). The CLQ (Asher \& Wheeler, 1985) is a 24-item questionnaire that assesses children's feelings of loneliness, social adequacy, and subjective estimations of peer status. The questionnaire was originally designed on a population of third-grade and sixth-grade children (Asher \& Wheeler, 1985); however, it has since been used with youth up to age 18 years (e.g., Michalski, Mishna, \& Worthington, 2003; Prinstein \& La Greca, 2002; Storch, Brassard, \& Masia-Warner, 2003). Children are asked to rate each statement on a 5-point scale ranging from that's always true about me to that's not true at all about me. Eight items on the CLQ are "filler" items and are not scored. The CLQ has good internal consistency with an alpha of .90 for the 16 primary items (Asher \& Wheeler, 1985). The validity of the CLQ distinguishing social status of children has also been established (Asher \& Wheeler, 1985).

Coopersmith Self-Esteem Inventory (SEI). The SEI (Coopersmith, 1981) contains 58 items that measure children's attitudes about themselves in social, academic, family, and personal areas of experience. The SEI concept of self-esteem refers to the child's approval or disapproval of himself or herself and was designed for children ages 7 to 16 years. Respondents are asked to check like me or unlike me to each item. For the SEI, high scores correspond to high self-esteem. The SEI has adequate internal consistency with alphas ranging from .80 to .92 and adequate construct and concurrent validity (Coopersmith, 1981).

Revised Children's Manifest Anxiety Scale (R-CMAS). The R-CMAS (Reynolds \& Richmond, 1985) is a 37item self-report measure that assesses general anxiety in children and adolescents ages 6 to 19 years. Respondents are asked to circle yes or no responses to 
each item. The Total Anxiety score is based on 28 items pertaining to physiological, subjective, and motor symptoms of anxiety. Reliability has been established with the R-CMAS (alpha = .83).

Weekly Problems Scale-Child Version (WPS-C). The WPS-C (Futa et al., 2004) was developed by Project SAFE researchers to provide a brief, efficient means of assessing multiple domains of child functioning. The scale consists of 11 statements (e.g., "I feel sad," "I get along with my friends"), and children are asked to mark one of six responses (i.e., never, almost never, a little of the time, some of the time, most of the time, all of the time) that best describe their feelings and interactions during the past week. Higher scores on each scale are indicative of problems in functioning in the assessed domain. See Table 3 for a complete list of the 11 items.

\section{Parent Measures}

Adult participants in the current study completed the following instruments (listed in alphabetical order).

Child Behavior Checklist (CBCL). The CBCL (Achenbach, 1991) is a 113-item checklist used for the assessment of parents' perceptions of social competence and behavioral problems of their children. It is designed for use with parents of children between the ages of 4 and 18 years. Parents are asked to rate the presence of problem behaviors in the previous 7 months on a 3point scale ranging from 0 (not true) to 3 (very true or often true). The CBCL scales have been standardized, taking into account age and gender. The CBCL is an instrument with well-established reliability and validity (Achenbach, 1991).

Child History Form (CHF). The CHF is an unstructured interview that collects relevant abuse-related information that was developed for this treatment program. The CHF is completed by one of the Project SAFE staff members as parents provide information about the abuse in their own words. Abuse characteristics gathered include age at onset and end of abuse, abuse duration, relationship to perpetrator, frequency of abuse, number of times abused, nature of abuse, and intrusiveness of abuse.

Child Sexual Behavior Inventory-2nd Version (CSBI2). The CSBI-2 (Friedrich et al., 1992) is a 35 -item inventory completed by parents on the frequency of various sexual behaviors pertaining to sexual aggression, self-stimulation, gender-role behavior, and personal boundary violation observed in their children ages 2 to 12 years. The CSBI- 2 demonstrates reliability (e.g., alpha coefficient to be .82 for a normative sample and .93 for a clinical sample of children with a confirmed history of sexual abuse) and validity (Friedrich et al., 2001).

Family Adaptability and Cohesion Evaluation Scales (FACES-III). The FACES-III (Olson, 1986) is a 20item self-report measure that assesses adaptability, cohesion, and family satisfaction. The FACES-III is actually taken twice to assess the respondent's perceptions of the current and ideal family systems using a 5-point scale from almost never to almost always. The higher the cohesion score, the more enmeshed the family is said to be. The higher the adaptability score, the more chaotic it is. For purposes of the current study, only the Adaptability-Now and Cohesion-Now Scales were used in analyses as they were thought to be more relevant to responses about current child and family functioning than were the Ideal Scales. The FACES-III has fair internal consistency with alphas ranging from .62 to .77 and good face validity (Olson, 1986).

Family Crisis Oriented Personal Evaluation Scales (FCOPES). F-COPES (McCubbin, Olson, \& Larsen, 1987 ) is a 30-item measure to assess effective problemsolving coping attitudes and behavior used by families in response to problems or difficulties. Two dimensions of family interactions are assessed by the F-COPES: internal family strategies (i.e., resources within the nuclear family system) and external family strategies (i.e., behaviors used to acquire resources outside of the family). F-COPES has an internal consistency of .86 and demonstrates good factorial validity and concurrent validity with other family measures.

Weekly Problems Scale-Parent Version (WPS-P). The WPS-P (Futa et al., 2004) was developed by Project SAFE researchers as a companion to the WPS-C to allow for the collection of relevant information from dual informants. It consists of 15 statements (e.g., "During the past 7 days my child appeared unhappy, sad, or depressed," "During the past 7 days my child argued or fought with others"). Parents are asked to rate each statement on a scale from 1 (never) to 10 (always). Higher scores on each scale are indicative of problems in functioning in the assessed domains. See Table 3 for a complete list of the 15 items.

\section{Procedures}

Data for the current study come from an ongoing clinical treatment program (Project SAFE), and the procedures described below reflect those of this program. A brief description of the Project SAFE procedures is relevant for understanding the context in which the current study was conducted. 
Families who expressed interest in participating in Project SAFE groups were contacted by the project coordinator and screened based on the inclusion and exclusion criteria for the intervention. Potential participants were informed that, as part of their involvement in Project SAFE groups, they would be asked to complete questionnaires that assist the therapists in understanding their family's difficulties and how to better serve families who are experiencing similar problems. Parents or guardians gave informed consent for their own participation and their children's participation. Youth also provided assent to participate in the study. The informed consent and assent procedures described the group intervention and research goals of the project. Children and parents separately completed the assessment measures. Modest payments of $\$ 20$ were made for each family after completion of the pretreatment assessment measures.

Families who participated in the Project SAFE groups completed the Weekly Problems Scales (i.e., WPS-C and WPS-P) at the pretreatment and posttreatment assessments and weekly throughout the course of treatment. All of the additional measures described above were completed only at the pretreatment assessment. At each data collection time, children and caregivers were supervised by graduate students who were available to answer questions and assist with reading. Fifty youth who were sexually abused and 48 parents who were nonoffending received the standardized 12 -session Project SAFE group treatment. Procedures used in sessions were psycho-educational, skill building, problem solving, and supportive. Child and parent groups each met concurrently for 90 -minute sessions. Project SAFE services are provided in the Psychological Consultation Center of the Department of Psychology at University of Nebraska-Lincoln (UNL) and at the local Child Advocacy Center. Groups are cofacilitated by therapists who are doctoral students in the clinical psychology program at UNL.

\section{RESULTS}

\section{Descriptive Information on Victimization History}

Perpetrators' demographic characteristics as reported by the parents who were nonoffending. Most of the child victims were abused by only 1 perpetrator $(n=54$, 84.4\%). Victims who had multiple offenders included eight victims who had 2 perpetrators $(12.5 \%)$ and two victims had 3 perpetrators (3.1\%). Of all the perpetrators identified by the parents who were nonoffending
TABLE 1: Characteristics

\begin{tabular}{|c|c|c|}
\hline Abuse Dimensions & $n$ & $\%$ \\
\hline \multicolumn{3}{|l|}{ Perpetrators' relationship to the child } \\
\hline Male sibling & 10 & 13.2 \\
\hline Biological father & 9 & 11.8 \\
\hline Parent's boyfriend & 9 & 11.8 \\
\hline Adult male family friend & 8 & 10.5 \\
\hline Male neighbor & 7 & 9.2 \\
\hline Child male family friend & 6 & 7.9 \\
\hline Stepfather & 5 & 6.6 \\
\hline Grandfather & 5 & 6.6 \\
\hline Male peer & 4 & 5.3 \\
\hline Other male family member & 3 & 3.9 \\
\hline Child female family friend & 3 & 3.9 \\
\hline Male babysitter & 2 & 2.6 \\
\hline Biological mother & 1 & 1.3 \\
\hline Adoptive father & 1 & 1.3 \\
\hline Female babysitter & 1 & 1.3 \\
\hline Male teacher and/or coach & 1 & 1.3 \\
\hline Male stranger & 1 & 1.3 \\
\hline \multicolumn{3}{|l|}{ Sexual abuse behaviors } \\
\hline Fondling & 49 & 76.6 \\
\hline $\begin{array}{l}\text { Oral contact (abuser to child's ge } \\
\text { child to abuser's genitals) }\end{array}$ & 18 & 28.1 \\
\hline Vaginal intercourse & 12 & 18.8 \\
\hline Digital penetration & 10 & 15.6 \\
\hline Viewing pornography & 5 & 7.8 \\
\hline $\begin{array}{l}\text { Child performing acts on anothe } \\
\text { (excluding offender) }\end{array}$ & 5 & 7.8 \\
\hline Anal intercourse & 3 & 4.7 \\
\hline Other (e.g., verbal sexual abuse) & 2 & 3.2 \\
\hline \multicolumn{3}{|c|}{ Use of force to gain compliance or secrecy } \\
\hline Unknown & 31 & 48.4 \\
\hline Yes & 12 & 18.8 \\
\hline No & 21 & 32.8 \\
\hline
\end{tabular}

NOTE: The total number of perpetrators is 76 for the 64 children because of the experience of some children having multiple perpetrators.

Because of multiple forms of sexual abuse that were experienced by the victims, the percentages of sexual abuse behaviors do not add up to 100 .

$(N=76), 34(44.7 \%)$ were family members (e.g., biological fathers, siblings, and other relatives), and 42 (55.3\%) were nonfamily members (e.g., neighbor, family friends, and peers). The perpetrators' relationship to the child victims is summarized in Table 1 . The majority of the perpetrators were boys or men $(n=71$, 93.4\%). Twenty-two offenders were children or adolescents (i.e., age 18 years or younger) whereas 47 were adults. Seven offenders' ages were unknown. Perpetrators ranged in age from 10 to 69 years, with a mean of 29.17 years $(S D=14.17)$.

Abuse characteristics. According to the parents who were nonoffending, only two children experienced noncontact forms (i.e., exposure by perpetrator and pornography, sexual solicitation) of sexual abuse. 
Thus, the majority of victims in the current sample experienced some form of contact abuse. Thirty-four victims were raped (54.0\%) such that they experienced some form of penetration (i.e., anal, oral, vaginal, or digital). The most common type of sexual abuse behaviors identified in this sample was fondling (76.6\%). Regarding the frequency of the sexual abuse, parents who were nonoffending estimated that 23 children (35.9\%) experienced one or two abuse incidents and 26 children (40.7\%) endured multiple acts of abuse. Fifteen parents who were nonoffending (23.4\%) were unclear about the total number of abuse incidents. A summary of the abuse characteristics is described in Table 1.

Regarding abuse discovery, parents who were nonoffending indicated that the majority of child victims either made a report to a parent, a peer, or another adult $(n$ $=43,67 \cdot 2 \%)$. Other methods of disclosure include another family member making a report, perpetrator disclosing the abuse, physical evidence, abuse witnessed by a third party, and the child sexually acting out leading to an investigation of sexual abuse. Abuse disclosure information was unknown to four parents who were nonoffending. Twenty-seven children (42.3\%) had been abused within 6 months of the interview while 32 (49.9\%) had been abused more than 6 months prior to the interview; the duration between the end of the abuse and the interview was unknown for 5 children (7.8\%).

Parents who were nonoffending reported the mean age at which the abuse began for 64 victims was 8.7 $(S D=3.1$, ranging from less than 1 year to 15 years $)$ and the mean age at which the abuse ended for 64 victims was 10.0 ( $S D=3.0$, ranging from 3 to 16 years). The duration of the abuse ranged from 1 to 90 months, with a mean duration of 15.0 months $(S D=21.2)$.

\section{Scale Identification}

Weekly Problems Scale items were initially developed to address the domains of negative mood, problem behavior, problem interactions with others, and abuserelated emotional and communication problems based on a theoretical perspective derived from our review of the literature on the effects of CSA. An exploratory factor analysis was conducted on the WPS-C and the WPS-P to identify statistically the number of underlying dimensions in the scales, to determine which sets of items measured similar constructs, and to verify the existence of the intended domains. Despite the small sample size, this combined method was viewed as preferable to relying solely on rationally derived scales. The WPS-C and WPS-P were factor analyzed using principal components extraction and varimax rotation. In the initial factor analysis, one item on the WPS-P (i.e., "I felt stressed as a parent") did not load high on any subscale, so it was removed from the analyses, and the factor analysis was redone. However, the item was retained in the full measure given the clinical relevance, future research interest in this item, and its good contribution to the internal consistency to the WPS-P.

In the final factor analysis, a three-factor solution was selected for the WPS-C which had eigenvalues higher than 1 and explained $63.84 \%$ of the variance: $34.01 \%, 20.48 \%$, and $9.32 \%$, respectively. A four-factor solution was chosen for the WPS-P based on the final statistics which had eigenvalues higher than one and explained $69.76 \%$ of the variance: $36.37 \%, 15.40 \%$, $10.01 \%$, and $7.99 \%$, respectively. Items were included on a factor if the item loading was .40 or higher; when an item loaded onto two factors, the largest factor loading was used to determine placement (see Tables 2 and 3 for

Table 2: $\quad$ Factor Pattern Matrix for Items on the Weekly Problems Scale-Child Version

\begin{tabular}{|c|c|c|c|c|}
\hline \multirow{2}{*}{\multicolumn{2}{|c|}{ Item Number and Description }} & \multicolumn{3}{|c|}{ Factors } \\
\hline & & 1 & 2 & 3 \\
\hline 1 & I feel sad. & $.630^{\mathrm{b}}$ & .227 & .440 \\
\hline 2 & I feel nervous or worry about things. & $.700^{\mathrm{b}}$ & -.033 & .359 \\
\hline 4 & I argue or fight with people & $.812^{\mathrm{b}}$ & -.213 & -.113 \\
\hline 5 & I get yelled at or get into trouble. & $.785^{\mathrm{b}}$ & .144 & -.022 \\
\hline 8 & I feel guilty about things that have happened. & $.638^{\mathrm{b}}$ & .239 & .336 \\
\hline 6 & I get along with my friends. ${ }^{\mathrm{a}}$ & .070 & $.556^{\mathrm{b}}$ & .070 \\
\hline 9 & I have good talks with him or her (nonoffending parent). ${ }^{a}$ & .090 & $.835^{\mathrm{b}}$ & -.080 \\
\hline 10 & I get along with him or her (nonoffending parent). ${ }^{\mathrm{a}}$ & .087 & $.750^{\mathrm{b}}$ & .326 \\
\hline 11 & I feel like he or she (nonoffending parent) is good to me. ${ }^{a}$ & -.102 & $.835^{\mathrm{b}}$ & .262 \\
\hline 3 & $\begin{array}{l}\text { I like myself. } \\
.440^{\mathrm{b}}\end{array}$ & .138 & .046 & \\
\hline 7 & $\begin{array}{l}\text { I feel like I am as good as other kids. } \\
.649^{\mathrm{b}}\end{array}$ & .121 & .366 & \\
\hline
\end{tabular}

NOTE: a. Items that were reverse scored. 
factor pattern matrices).

The WPS-C three factors were named: Negative Moods and Behaviors (NMB-C; five items), Problem Peer and Parental Interactions (PPPI-C; four items), and Self-Esteem Problems (SEP-C; two items). The WPS-P four factors were identified as Problem Behaviors (PB-P; four items), Parenting and Family Problems (FPF-P; four items), Sex and Sexual Abuse Communication Issues (SSACI-P; two items), and Negative Moods (NM-P; four items). The factors that were derived from the analyses largely correspond with the rationally derived domains and, therefore, lend support to the use of these subscales. The one difference is that NMB-C was a single factor for the WPS-C.

Given the difference in content and relatively smaller factor loading for the item "I got along with my friends" on the PPPI-C subscale, psychometrics were examined with and without the item retained in the subscale. Removal of the item resulted in a comparable internal consistency (i.e., .80 with the item retained vs. .81 with the item excluded). Because of the acceptable factor loading (.556) and the negligible change in internal consistency, the item was retained. However, the revised subscale could have value for those purely interested in problem parental interactions.

All three subscales of the WPS-C (i.e., NMB-C, PPPI-C, SEP-C) were included in an additive manner to create the WPS-C Total Scale. Higher scores on the scales reflect higher number of problems in the respective domains of functioning. The WPS-P Total Scale is created by summing together three of the four subscales
(PB-P, PFP-P, and NM-P) and the single item that was not included in any of the subscales (i.e., "I felt stressed as a parent"). Similar to the WPS-C, higher scores on the scales are indicative of greater problems in the assessed domains of functioning.

The exclusion of the SSAC-P in the WPS-P Total Scale was decided for two specific reasons. First, the frequency of communication on issues of sex and sexual abuse between parent and child is likely to be variable from week to week. Parents and children may go weeks without any discussion surrounding the subjects of sex and sexual abuse and then have time periods with frequent discussion. Because of the variable nature of discussion on these topics, it was thought that the rating of the SSAC-P subscale items would be less stable than the other items measured on the WPS-P. Therefore, inclusion of the SSAC-P subscale in the WPS-P Total Scale would reduce the reliability of the Total Scale. Second, the interpretation of the items on the SSAC-P subscale is different than items on the other subscales. Similar to other subscales, consistent high scores on the SSAC-P subscale is likely indicative of a problem. Those parents and children who frequently discuss issues surrounding sex and the sexual abuse may do so because of occurring problems. For instance, a child who exhibits more sexual behavior may require more frequent discussions from the parent. These parents may find it necessary to ask more questions and inquire regularly. Unlike the other subscales, consistent low scores on the SSAC-P subscale may also be indicative of a problem relationship between parent and child (e.g., general

TABLE 3: Factor Pattern Matrix for Items on the Weekly Problems Scale-Parent Version

\begin{tabular}{|c|c|c|c|c|c|}
\hline \multirow{2}{*}{\multicolumn{2}{|c|}{ Item Number and Description }} & \multicolumn{4}{|c|}{ Factors } \\
\hline & & 1 & 2 & 3 & 4 \\
\hline 4 & $\begin{array}{l}\text { My child was noncompliant (e.g., did no follow my } \\
\text { directions, did not follow my family rules). }\end{array}$ & $.734^{\mathrm{b}}$ & .299 & -.220 & -.109 \\
\hline 5 & My child argued or fought with others (e.g., other kids). & $.735^{\mathrm{b}}$ & .240 & .069 & .213 \\
\hline 6 & My child was restless, hyperactive, or could not sit still. & $.822^{\mathrm{b}}$ & -.066 & .118 & -.018 \\
\hline 7 & My child interacted and got along well with friends own age. ${ }^{a}$ & $.656^{\mathrm{b}}$ & .309 & .036 & .178 \\
\hline 8 & My child interacted and got along well with rest of the family. ${ }^{a}$ & .326 & $.613^{\mathrm{b}}$ & -.317 & .205 \\
\hline 12 & I felt like I was a competent parent. ${ }^{\mathrm{a}}$ & -.132 & $.625^{\mathrm{b}}$ & .477 & .026 \\
\hline 13 & My child and I were able to communicate well with one another. ${ }^{a}$ & .275 & $.891^{\mathrm{b}}$ & -.006 & .173 \\
\hline 14 & My child and I interacted well together. ${ }^{a}$ & .321 & $.849^{\mathrm{b}}$ & .002 & .207 \\
\hline 9 & My child and I talked about sex-related issues. & .048 & .059 & $.858^{\mathrm{b}}$ & .017 \\
\hline 10 & My child and I talked about some aspect of the sexual abuse. & .034 & -.094 & $.860^{\mathrm{b}}$ & .209 \\
\hline 1 & $\begin{array}{l}\text { My child appeared unhappy, sad, or depressed. } \\
.698^{\mathrm{b}}\end{array}$ & .315 & .318 & .013 & \\
\hline 2 & $\begin{array}{l}\text { My child appeared nervous, tense, or anxious. } \\
.553^{\mathrm{b}}\end{array}$ & .458 & .191 & -.080 & \\
\hline 3 & $\begin{array}{l}\text { My child appeared to feel good about herself or himself. } \\
.539^{\mathrm{b}}\end{array}$ & .407 & .330 & .269 & \\
\hline 11 & $\begin{array}{l}\text { My child appeared to feel guilty or ashamed about the sexual abuse. } \\
.831^{\mathrm{b}}\end{array}$ & -.130 & .029 & .153 & \\
\hline
\end{tabular}

NOTE: a. Items that were reverse scored. 
lack of communication between the parent-child Never communicating about issues surrounding either sex or the sexual abuse may speak to the nature of the dyad, a lack of comfort discussing sensitive topics). Therefore, consistent scores at either extreme on the SSAC$\mathrm{P}$ subscale are not desired and may reflect problems in functioning. Because of the variable nature of the items on the SSAC-P subscale and their unique interpretation, it was decided that the subscale would not be included in the WPS-P Total Scale. However, any therapist using the WPS-P should regularly assess the pattern of the items on the SSAC-P subscale to determine if intervention or further assessment is necessary.

\section{Internal Consistency and Relationships Among Subscales}

Reliability analyses of the WPS-C and the WPS-P were conducted to examine whether the items on the total scale and each of the subscales tended to be answered the same way (coefficient alphas). Item-total statistics were examined for each subscale and the full scale using Corrected Item-Total Correlations (CITC) to determine which items should remain in the scale. No items generated CITC's < .3 (i.e., not considered items that loaded well on the total scale or subscales), and thus, all items were retained.

Clear standards indicating what level of reliability is perceived as acceptable are not available (Clark \& Watson, 1995). Researchers have considered .60s and .70s reliabilities as good, adequate, or minimally acceptable, particularly in the early stages of test development (e.g., Dekovic, Janssens, \& Gerris, 1991; DeVellis, 1991; Holden, Fekken, \& Cotton, 1991; Nunnally \& Bernstein, 1994). However, Clark and Watson (1995) suggested that alpha coefficients be at least .80 to be regarded as acceptable. Coefficient alphas for the total scales were calculated first to determine the overall internal consistency of the full set of items, WPS-C Total Scale alpha $=.791$ and WPS-P Total Scale alpha $=$ .856. Because the WPS-C and the WPS-P consist of separate, rationally derived subscales that may tap constructs that are not necessarily related, the internal consistencies of the separate subscales were evaluated next. WPS-C and WPS-P alpha coefficients and correlations between the subscales and the total scale score are presented in Tables 4 and 5, respectively. Overall, the values of the total scales and the subscales fall within the estimate of acceptable internal consistency. The SEP$\mathrm{C}$ alpha value (.61) was the only subscale to be on the low end of adequate internal consistency, possibly because it consists of only two items (Nunnally \& Bernstein, 1994).

Based on these initial calculations, the WPS-C and the WPS-P total scales and their subsequent subscales

TABLE 4: Alpha Coefficients and Intercorrelations Among Weekly Problems Scale-Child Version Subscales and Total Scale

\begin{tabular}{|c|c|c|c|c|c|}
\hline & \multicolumn{5}{|c|}{ Correlations } \\
\hline & $\alpha$ & $N M B-C$ & PPPI-C & $S E P-C$ & WPS-C TOT \\
\hline NMB-C (5 items) & .798 & 1.00 & & & \\
\hline PPPI-C (4 items) & .765 & .183 & 1.00 & & \\
\hline SEP-C (2 items) & .613 & $.363^{*}$ & $.410 *$ & 1.00 & \\
\hline WPS-C TOT ( 11 items) & .791 & $.804 *$ & $.680^{*}$ & $.692 *$ & 1.00 \\
\hline
\end{tabular}

NOTE: NMB-C = Negative Moods and Behaviors subscale-Child Version; PPPI-C = Problem Peer and Parental Interactions subscale-Child Version; SEP-C = Self-Esteem Problems subscale-Child Version; WPS-C TOT = Weekly Problem Scale-Child Version: Total Scale. $* p<.01$

TABLE 5: Alpha Coefficients and Intercorrelations Among Weekly Problems Scale-Parent Version Subscales and Total Scale

\begin{tabular}{|c|c|c|c|c|c|c|}
\hline & \multicolumn{6}{|c|}{ Correlations } \\
\hline & $\alpha$ & $P B-P$ & $P F P-P$ & $N M-P$ & WPS-P TOT & $S S A C-P$ \\
\hline PB-P (4 items) & .781 & 1.00 & & & & \\
\hline PFP-P ( 4 items) & .797 & $.380 *$ & 1.00 & & & \\
\hline NM-P (4 items) & .736 & $.467 *$ & $.323 *$ & 1.00 & & \\
\hline WPS-P TOT (13 items) & .856 & $.812^{*}$ & $.635^{*}$ & $.831 *$ & 1.00 & \\
\hline SSAC-P (2 items) & .777 & .049 & -.011 & .226 & .139 & 1.00 \\
\hline
\end{tabular}

NOTE: PB-P = Problem Behaviors subscale-Parent Version; PFP-P = Parenting and Family Problems subscale-Parent Version; NMB-P = Negative Moods subscale-Parent Version; WPS-P TOT = Weekly Problem Scale-Parent Version: Total Scale; SSAC-P = Sex and Sexual Abuse Communication Issues subscale-Parent Version.

$* p<.01$ 
appear to be internally consistent and were considered reliable. Therefore, subsequent attempts to improve the internal consistency of the subscales were not necessary.

Last, we examined the interrelationships between the WPS-C and WPS-P subscales which are presented in Table 6. As expected, results indicate that the total scales of the two measures correlate significantly (.338). In reference to specific subscales, correlations were in the expected direction among those subscales that were thought to be related. For instance, the NMB-C on the WPS-C significantly correlated with the PB-P and NM-P subscales of the WPS-P. In addition, the SEP-C significantly correlated with the NM-P subscale. Given the differences in content assessed among the individual subscales and between the measures, it was not anticipated that each of the subscales would be intercorrelated. For instance, the WPS-C does not have parallel questions for those assessed in the SSAC-P subscale of the WPS-P; therefore, we did not anticipate significant correlations between it and other subscales.

\section{Temporal Stability}

Test-retest reliability was assessed for the WPS$\mathrm{C}$ and WPS-P using the full scales and the individual subscales (Table 7). As discussed previously, participants completed the WPS-C and WPS-P at each of the 12 sessions of treatment and at posttreatment. For purposes of the analyses, three-session intervals were created to simplify the process of assessing test-retest reliability for the 12 sessions of treatment. Given the repeated nature of the assessment process, we were not able to have $100 \%$ completion by all parents and children each week. Approximately $18 \%$ of parents and youth were missing one or more data points. However, nearly $89 \%$ of the total data were available. Correlations were computed for those questionnaires administered 1 to 3 sessions apart,
4 to 6 sessions apart, 7 to 9 sessions apart, and 10 to 11 sessions apart. In the majority of cases, the time interval between sessions was 1 week with the occasional exception because of holidays. Because families were administered the measures during treatment, it was expected that test-retest reliability correlations would be greatest at shorter intervals and decrease slightly as time and treatment progressed.

For the WPS-C Total Scale, results reveal a stepwise decrease in temporal stability across time with an average .880 correlation for the 1 -to-3-session interval to an average .716 correlation for the 10 -to-11-session interval. In addition, correlations of posttreatment scores with the final session of treatment were greater than with the first session of treatment (.916 and .775, respectively). Results demonstrated a similar pattern for the WPS-P Total Scale with an average .559 correlation for the 1-to-3-session interval to an average .374 correlation for the 10-to-11-session interval. As expected, posttreatment correlations on the WPS-P Total Scale were greater for the final session of treatment (.815) than for the first session of treatment (.417). To provide some perspective, in the original correlation matrix, correlations above .380 were significant at the .05 level. Therefore, it is likely that each of the above average correlations were statistically significant with the potential exception of the WPS-P Total Scale 10-to11-session average correlation.

A similar pattern of decreasing correlations emerged for each of the subscales on the WPS-C. The WPS-C subscales all demonstrated excellent temporal stability, and each scale was consistent with the test-retest correlations of the WPS-C Total Scale. Results also demonstrated a similar correlation pattern on the WPS-P subscales with the exception of the PB-P subscale, which had relatively stable correlation averages throughout the intervals.As expected, the SSAC-P subscale average

TABLE 6: Correlation Between Weekly Problems Scale-Child Version Subscales and Total Scale and Weekly Problems Scale-Parent Version Subscales and Total Scale

\begin{tabular}{lccc}
\hline & NMB-C (5 items) & PPPI-C (4 items) & SEP-C (2 items) \\
\hline PB-P (4 items) & $.273^{*}$ & .179 & .162 \\
PFP-P (4 items) & $.254^{*}$ & .221 & $.138^{*}-293^{*}$ \\
NM-P (4 items) & $.301^{*}$ & .132 & $.298^{*}$ \\
WPS-P TOT (13 items) & $.316^{*}$ & .205 & .185 \\
SSAC-P (2 items) & $.208^{*}$ & -.105 & .095 \\
\hline
\end{tabular}

NOTE: NMB-C = Negative Moods and Behaviors subscale-Child Version; PPPI-C = Problem Peer and Parental Interactions subscale-Child Version; SEP-C = Self-Esteem Problems subscale-Child Version; WPS-C TOT = Weekly Problem Scale-Child Version: Total Scale; PB-P = Problem Behaviors subscale-Parent Version; PFP-P = Parenting and Family Problems subscale-Parent Version; NMB-P = Negative Moods subscale-Parent Version; WPS-P TOT = Weekly Problem Scale-Parent Version: Total Scale; SSAC-P = Sex and Sexual Abuse Communication Issues subscale-Parent Version.

$* p<.05 . * * p<.01$ 
correlations were relatively less stable and indicated that the frequency with which families and children discuss issues of sex and sexual abuse is more variable, particularly over longer time periods. These results verify our decision to exclude the SSAC-P subscale from the WPS-P Total Score.

\section{Construct Validity}

Construct validity was assessed to determine if the WPS-C and WPS-P are related to other measures that are thought to assess similar constructs. Pearson correlations were calculated to examine the relationships between the WPS-C and WPS-P full scales and subscales with parent report on the CBCL Internalizing Problems Scale, CBCL Externalizing Problems Scale, CBCL Total Problems Scale, CSBI-2 Total Score, FACES-III-Adaptability Now Scale, FACES-III Cohesion Now Scale, and F-COPES Total Score, and child report on the CDI Total Score, R-CMAS Total Anxiety Scale, CFRV Total Score, CITES-R PTSD Scale, CITES-R Social Reactions Scale, CITES-R Eroticism Scale, CITES-R Attribution Scale, CLQ Total Score, and SEI Total Self Scale. These analyses are summarized in Table 8.

The WPS-C Total Scale demonstrated modest but significant correlations with each of the CBCL scales and moderate to strong correlations with all of the child report measures. This pattern was to be expected given prior findings that agreement between parents and child self-reports are generally modest. In general, research has demonstrated that children appear to be more accurate reporters of their internal states (e.g., self-esteem, anxiety, depression) whereas parents are better reporters on externalizing behaviors (e.g., fighting, acting out behaviors; Grych, Seid, \& Fincham, 1992). A similar correlation pattern was found for the Negative Moods and Behaviors subscale (NMB-C). The CBCL scales were not significantly correlated with the PPPI-C subscale or the SEP-C subscale; however, correlations with child report measures were in the expected directions. For instance, strong correlations existed between the SEP$\mathrm{C}$ and the CDI (.642), CLQ (.553), and SEI (-.552). No significant correlations were found between any of the WPS-C scales and the FACES-III scales or FCOPES. While these findings were not what were expected, on further examination they are not surprising given the lack of focus on family cohesiveness, adaptability to change, or effectiveness of problem-solving strategies on the WPS-C.

Correlations for the WPS-P Total Scale were also in the expected direction. Strong correlations were found with each of the parent report measures assessing child symptomatology (i.e., CBCL scales and CSBI-2), whereas there were moderate correlations with many of the child report measures. However, it should also be noted that it had moderate correlations with many of the measures that assessed internalizing. The PB-P subscale demonstrated a similar pattern and, as expected, had the highest correlations of any of the subscales with the CBCL Externalizing (.612) and Total scales (.607). The PFPI-P subscale had moderate correlations with the CBCL and CSBI-2 but also demonstrated an anticipated moderate negative correlation with the FACES-III-Cohesion Scale (-.474). These results suggest that poor familial interactions and problems with parenting as measured by the PFPI-P subscale are related to a lack of family cohesion and a general interactional

TABLE 7: Temporal Stability: Average Correlations of the Total Scale Scores and Subscale Scores Across Increasing Intervals

\begin{tabular}{|c|c|c|c|c|}
\hline \multirow[b]{2}{*}{ Scales } & \multicolumn{4}{|c|}{ Session Intervals } \\
\hline & 1 to 3 & 4 to 6 & 7 to 9 & 10 to 11 \\
\hline \multicolumn{5}{|c|}{ Weekly Problems Scale-Child version } \\
\hline WPS-C TOT & .880 & .829 & .783 & .716 \\
\hline NMB-C & .844 & .800 & .751 & .630 \\
\hline PPPI-C & .826 & .739 & .609 & .548 \\
\hline SEP-C & .807 & .759 & .705 & .635 \\
\hline \multicolumn{5}{|c|}{ Weekly Problems Scale-Parent version } \\
\hline WPS-P TOT & .559 & .439 & .387 & .374 \\
\hline PB-P .605 & .561 & .589 & .589 & \\
\hline PFP-P & .526 & .432 & .388 & .283 \\
\hline NM-P & .565 & .498 & .372 & .326 \\
\hline SSAC-P & .532 & .450 & .286 & .202 \\
\hline
\end{tabular}

NOTE: WPS-C TOT = Weekly Problem Scale-Child Version: Total Scale; NMB-C = Negative Moods and Behaviors subscale-Child Version; PPPI-C $=$ Problem Peer and Parental Interactions subscale-Child Version; SEP-C = Self-Esteem Problems subscale-Child Version; WPS-P TOT $=$ Weekly Problem Scale-Parent Version: Total Scale; PB-P = Problem Behaviors subscale-Parent Version; PFP-P = Parenting and Family Problems subscale-Parent Version; NMB-P = Negative Moods subscale-Parent Version; SSAC-P = Sex and Sexual Abuse Communication Issues subscale-Parent Version. 
style among the family of disengagement. As expected, the NM-P subscale had the highest correlation with the CBCL Internalizing scale (.443) and the highest correlations among the WPS-P subscales with the CDI (.374), R-CMAS (.342), CITESR-PTSD (.343), and SEI (-.261). However, it also correlated moderately with the CBCL Externalizing Scale (.344) and the CSBI-2 (.304). Given the lack of measures specifically assessing communication about the abuse and sex in general, no specific hypotheses were generated for the SSAC-P subscale; however, it was expected that there would be no strong correlations as scores at either extreme on the SSAC-P subscale are thought to be undesirable. Results indicate that the SSAC-P subscale was moderately correlated with the CBCL Internalizing scale (.308), CSBI-2 (.292), FACES-III-Adaptability Now scale (.354), and CDI (.321). These findings suggest that those children who are communicating frequently about sex or sexual abuse-related issues with their caregivers as measured by the SSAC-P subscale are experiencing higher levels of internalizing symptoms, increased sexualized behavior, and living in a family that is more chaotic and less adaptable to change.

The correlations between the Weekly Problems Scales and the other child and parent report measures reveal many statistically significant relationships in the appropriate directions. Therefore, evidence exists for construct validity with regard to the theoretical connections between the measures.

\section{DISCUSSION}

The Weekly Problems Scales were developed because of the lack of brief and efficient assessment measures designed to monitor progress in multiple domains of functioning in children who are sexually abused and in treatment. Creation of the WPS-C and WPS-P focused on the assessment of three critical target areas impacted by sexual abuse (i.e., the individual or "self," relationships, and sex). The current study identified the underlying dimensions of the scales and evaluated the psychometric properties of the WPS-C and WPS-P.

An exploratory factor analysis was used in conjunction with rational reasoning to identify subscales for each of the Weekly Problems Scales. Three subscales were identified for the WPS-C: NMB-C, PPPI-C, and SEP-C. For the WPS-P, four subscales were named: PBP, PFP-P, NM-P, and SSAC-P. While the sample size in the current study is not ideal for factor analysis, the principal components solutions largely correspond

TABLE 8: Correlations Between Weekly Problems Scale Subscales and Other Related Measures

\begin{tabular}{|c|c|c|c|c|c|c|c|c|c|}
\hline & $N M B-C$ & PPPI-C & $S E P-C$ & WPS-C TOT & $P B-P$ & PFPI-P & $N M-P$ & WPS-P TOT & $S S A C-P$ \\
\hline \multicolumn{10}{|l|}{ Parent report measures } \\
\hline CBCL-Internalizing & $.334^{* * *}$ & .140 & .231 & $.336^{* *}$ & $.442 * *$ & $.410^{* *}$ & $.443^{* *}$ & $.544^{* * *}$ & $.308 *$ \\
\hline CBCL-Externalizing & $.399 * *$ & .239 & .161 & $.402^{* * *}$ & $.612 * *$ & $.422 * *$ & $.344^{* *}$ & $.576^{* * *}$ & .094 \\
\hline CBCL-Total & $.432 * *$ & .193 & .203 & $.413^{* *} *$ & $.607 * *$ & $.417^{* *}$ & $.404^{* *}$ & $.599 * *$ & .211 \\
\hline CSBI-2 & $.274 *$ & .064 & .104 & .229 & $.391 * *$ & $.256^{*}$ & $.304^{*}$ & $.403^{* * *}$ & $.292 *$ \\
\hline FACES-III-Adaptability Now & .074 & .010 & -.075 & .028 & -.028 & -.040 & $.256^{*}$ & .120 & $.354 *$ \\
\hline FACES-III-Cohesion Now & -.209 & -.094 & -.093 & -.193 & .077 & $-.474 * *$ & -.076 & -.153 & -.027 \\
\hline F-COPES & -.178 & -.103 & .055 & -.141 & -.168 & -.219 & -.239 & $-.268 *$ & .087 \\
\hline \multicolumn{10}{|l|}{ Child report measures } \\
\hline CDI & $.605^{* *}$ & $.438 * *$ & $.642^{* * *}$ & $.752^{* * *}$ & $.319 *$ & .185 & $.374^{* *}$ & $.389^{* *}$ & .090 \\
\hline R-CMAS & $.608^{* *}$ & $.259 *$ & $.423^{* * *}$ & $.613^{* *}$ & $.269 *$ & .163 & $.342 * *$ & $.325^{*}$ & $.321 *$ \\
\hline CFRV & $.266^{*}$ & .145 & .194 & $.285^{*}$ & .163 & .031 & .139 & .172 & .139 \\
\hline CITES-R-PTSD & $.577^{* *}$ & $.351^{* *}$ & $.435^{* * *}$ & $.628^{* *}$ & $.297 *$ & $.283^{*}$ & $.343^{* *}$ & $.386 * *$ & .059 \\
\hline CITES-R-Social Reactions & $.393^{* * *}$ & .143 & .193 & $.355^{* * *}$ & .048 & $.346^{* * *}$ & .092 & .241 & .181 \\
\hline CITES-R-Eroticism & $.316^{* * *}$ & .006 & .089 & .218 & .227 & .045 & .240 & .236 & -.050 \\
\hline CITES-R-Attributions & $.569 * *$ & .169 & $.364^{* *}$ & $.521^{* *}$ & $.302 *$ & .138 & .176 & $.263 *$ & .228 \\
\hline CLQ & $.389^{* * *}$ & $.355^{* *}$ & $.553^{* * *}$ & $.564^{* *}$ & $.347 * *$ & .151 & .224 & $.301 *$ & .013 \\
\hline SEI & $-.530 * *$ & $-.292^{*}$ & $-.552 * *$ & -.627 *** & -.118 & -.232 & $-.261 *$ & -.242 & -.041 \\
\hline
\end{tabular}

NOTE: NMB-C $=$ Negative Moods and Behaviors subscale-Child Version; PPPI-C $=$ Problem Peer and Parental Interactions subscale-Child Version; SEP-C = Self-Esteem Problems subscale Child Version; WPS-C TOT = Weekly Problems Scale—Child Version Total; PB-P = Problem Behaviors subscale-Parent Version; PFPI-P = Problem Family and Parental Interactions subscale-Parent Version; NM-P = Negative Moods subscale-Parent Version; WPS-P TOT = Weekly Problems Scale-Parent Version Total; SSAC-P = Sex and Sexual Abuse Communication Issues subscale-Parent Version; CBLC $=$ Child Behavior Checklist; CSBI-2 = Child Sexual Behavior Inventory-2nd version; FACES-III = Family Adaptability and Cohesion Evaluation Scale; F-COPES = Family Crisis Oriented Personal Evaluation Scales; CDI = Children's Depression Inventory; R-CMAS = Revised Children's Manifest Anxiety Scale; CFRV = Children'S Fears Related to Victimization; CITES-R = Children's Impact of Traumatic Events-Revised; CLQ = Children's Loneliness Questionnaire; SEI = The Self-Esteem Inventory. $* p<.05 . * * p<.01$. 
with the rationally derived subscales, and subsequent reliability and validity analyses begin to support the use of these subscales. However, the authors recommend primarily using the WPS Total Scales, as they are the most valuable and reliable, and using the WPS subscales for clinical indicators and teasing out problem areas, as they should be considered experimental until further psychometric properties are obtained.

The Weekly Problems Scales were found to have adequate internal consistency. Cronbach's alphas for the WPS-C Total Scale and WPS-P Total Scale were .791 and .856 , respectively, and the coefficient alphas for the subscales were acceptable. Temporal stability of the WPS-C and WPS-P was supported by consistent stepwise decreasing correlations for session intervals as time and treatment progressed. However, results revealed higher stability for the WPS-C than for the WPS-P. It is possible that the younger children in the sample may not be as good at making judgments about the specific 7-day time period as adults, and that the ability to focus on specific reference periods increases with age. Younger youth may be less able to focus on the reference period indicated and, instead, think of themselves and their interactions more globally and, therefore, more stably. Future research should continue to assess the temporal stability of the WPS-C and WPS-P as well as temporal stability in relation to specific age groups.

Finally, the construct validity of the Weekly Problems Scales was demonstrated by significant correlations with multiple well-validated child-report and parent-report assessment measures. Correlations were largely in the expected directions, and stronger correlations existed among the WPS subscales and other measures that were assessing similar constructs. For instance, strong correlations existed between the SEP-C and the CDI (Kovacs, 1992), the CLQ (Asher \& Wheeler, 1985), and the SEI (Coopersmith, 1981). Although the patterns were largely in the expected directions, there are some that need further assessment. For instance, the NM-P was strongly correlated with internalizing measures but also moderately correlated with externalizing measures. Given the experimental nature of the subscales, relatively small sample size, and the large number of correlations conducted, further research needs to be conducted to verify convergent and discriminant validity.

The WPS-C and WPS-P were intended to be reliable and useful brief assessment measures for researchers and practitioners in the assessment and evaluation of symptom change and progress in youth who were sexually abused and in treatment. The Weekly Problems Scales are unique in the development of complementary child and parent forms, their broad assessment of multi- ple domains of functioning, their ability to be used with a wide age group, and the brevity and efficiency of the measures. Thus far, the measures have been useful in ongoing clinical and research endeavors (Futa, 1998; Hsu, Sedlar, Flood, \& Hansen, 2002). In addition, the design of the current study allowed for the comparison of the WPS-C and WPS-P to multiple well-validated parentreport and child-report measures and multiple, repeated assessments of the WPS-C and WPS-P over treatment.

Future research on the Weekly Problems Scales should seek to obtain a larger sample to confirm the factor structure and further assess the reliability and validity of the scales. One factor structure issue to explore is whether additional items or a larger sample would result in a separation of the NMB-C into two subscales, resulting in a factor structure similar to the WPS-P. Although the current sample size is limited for a psychometric examination of a measure, it should be noted that within the field of CSA, this is a respectable initial sample size because of the challenges accessing participants for research in the area of CSA. In addition, the inclusion of a nonclinical, nonabused comparison sample should be a goal of future research to assist in examining the measures' sensitivity to change with different populations. However, the goal of the Weekly Problems Scales is not to differentiate between groups but to provide researchers and clinicians with useful, reliable, and valid information about the problems that are particularly characteristic of youth who are sexually abused. Last, additional attention to the assessment of sexual behavior problems and sexual acting would be of value and will be considered in future research.

In this sample, the WPS-C and WPS-P full scales and subscales demonstrated adequate internal consistency, test-retest reliability, and construct validity. Although further research needs to be conducted, it is believed that the WPS-C and WPS-P possess the potential to augment practitioner-based and researcher-based assessments in identifying areas of need in treatment and ascertaining the progress of youths in treatment. At present, there are no measures designed specifically for this purpose to be used with youth who are sexually abused, and the Weekly Problems Scales help to begin filling this gap.

\section{REFERENCES}

Achenbach, T. M. (1991). The Child Behavior Checklist manual. Burlington: University of Vermont.

Asher, S. R., \& Wheeler, V. A. (1985). Children's loneliness: A comparison of rejected and neglected peer status. Journal of Consulting and Clinical Psychology, 53, 500-505. 
Briere, J. (1995). Professional manual for the Trauma Symptom Checklist for Children (TSCC). Odessa, FL: Psychological Assessment Resources.

Briere, J. (1996). Treatment outcome research with abused children: Methodological considerations in three studies. Child Maltreatment, 1, 348-352.

Briere, J., \& Runtz, M. (1993). Childhood sexual abuse: Longterm sequelae and implications for psychological assessment. Journal of Interpersonal Violence, 8, 312-330.

Burkhardt, K., Loxton, H., \& Muris, P. (2003). Fears and fearfulness in South-African children. Behaviour Change, 20, 94-102.

Burlingame, G. M., Wells, M. G.,\&Lambert, M. J. (1996). Youth Outcome Questionnaire. Stevenson, MD: American Professional Credentialing Services.

Chaffin, M., \& Shultz, S. (1999). Psychometric evaluation of the Children's Impact of Traumatic Events Scale-Revised. Unpublished manuscript.

Clark, L. A.,\&Watson, D. (1995). Constructing validity: Basic issues in objective scale development. Psychological Assessment, 7, 309-319.

Cohen, J. A.,\&Mannarino, A. P. (1993). A treatment model for sexually abused preschoolers. Journal of Interpersonal Violence, 8, 115-131.

Cohen, J. A., \& Mannarino, A. P. (1996a). A treatment outcome study for sexually abused preschoolers: Initial findings. Journal of the American Academy of Child and Adolescent Psychiatry, 35, 42-50.

Cohen, J. A., \& Mannarino, A. P. (1996b). The Weekly Behavior Report: A parent-report instrument for sexually abused preschoolers. Child Maltreatment, 1, 353-360.

Cohen, J. A., \& Mannarino, A. P. (1998). Interventions for sexually abused children: Initial treatment outcome findings. Child Maltreatment, 3, 17-26.

Coopersmith, S. (1981). Self-esteem inventories. Palo Alto, CA: Consulting Psychologists Press.

Deblinger, E., Stauffer, L. B., \& Steer, R. A. (2001). Comparative efficacies of supportive and cognitive-behavioral group therapies for young children who have been sexually abused and their nonoffending mothers. Child Maltreatment, 6, 332-343.

Dekovic, M., Janssens, J. M. A. M., \& Gerris, J. R. M. (1991). Factor structure and construct validity of the Block Child Rearing Practices Report (CRPR). Psychological Assessment, 3, 182-187.

DeVellis, R. (1991). Scale development. Newbury Park, CA: Sage.

Friedrich, W. N., Fisher, J. L., Dittner, C. A., Acton, R., Berliner, L., Butler, J., et al. (2001). Child Sexual Behavior Inventory: Normative, psychiatric, and sexual abuse comparisons. Child Maltreatment, 6, 37-49.

Friedrich, W. N., Grambsch, P., Damon, L., Hewitt, S. K., Koverola, C., Lang, R. A., et al. (1992). Child Sexual Behavior Inventory normative and clinical comparisons. Psychological Assessment, 4, 303-311.

Futa, K. T. (1998). The development and initial evaluation of Project SAFE: A group treatment for sexually abused children and their nonoffending parents. Unpublished doctoral dissertation, University of Nebraska, Lincoln.
Futa, K. T., Hecht, D. B., \& Hansen, D. J. (1996, November). Working with sexually abused children and their nonoffending parents: A conceptualization and treatment. In J. R. Lutzker (Chair), Child abuse and neglect: The cutting edge. Symposium conducted at the meeting of the Association for the Advancement of Behavior Therapy, New York, NY.

Futa, K. T., Hecht, D. B., Sawyer, G. K.,\&Hansen, D. J. (2004). Manual for the Weekly Problems Scales: Parent and child versions. Lincoln: University of Nebraska-Lincoln Department of Psychology.

Grych, J. H., Seid, M., \& Fincham, F. (1992). Assessing marital conflict from the child's perspective: The Children's Perceptions of Interparental Conflict Scale. Child Development, 62, 558-572.

Hansen, D. J., Hecht, D. B., \& Futa, K. T. (1998). Child sexual abuse. In V. B. Van Hasselt \&M. Hersen (Eds.), Handbook of psychological treatment protocols for children and adolescents (pp. 153-178). Mahwah, NJ: Lawrence Erlbaum.

Holden, R. R., Fekken, G. C., \& Cotton, D. H. G. (1991). Assessing psychopathology using structured test-item response latencies. Psychological Assessment, 3, 111-118.

Hsu, E., Sedlar, G., Flood, M. F., \& Hansen, D. J. (2002). Child sexual abuse. In M. Hersen (Ed.), Clinical behavior therapy: Adults and children (pp. 449-473). New York: John Wiley.

Kendall-Tackett, K. A., Williams, L. M., \& Finkelhor, D. (1993). Impact of sexual abuse on children: A review and synthesis of recent empirical studies. Psychological Bulletin, 11, 164-180.

Kovacs, M. (1992). Children's Depression Inventory. North Tonawanda, NY: Multi-Health Systems.

Lambert, M. J., Hansen, N., Umphress, V., Lunnen, K., Okiishi, J., Burlingame, G., et al. (1996). Administration and scoring manual for the Outcome Questionnaire (OQ-45.2). Wilmington, DE: American Professional Credentialing Services.

Lambert, M. J., \&Hawkins, E. J. (2004). Measuring outcome in professional practice: Considerations in selecting and using brief outcome instruments. Professional Psychology: Research and Practice, 35, 492-499.

Mannarino, A. P., Cohen, J. A., \& Berman, S. R. (1994). The Children's Attributions and Perceptions Scale: A new measure of sexual abuse-related factors. Journal of Clinical Child Psychology, 23, 204-211.

McCubbin, H. I., Olson, D. H., \& Larsen, A. S. (1987). FCOPES: Family Crisis Oriented Personal Evaluation Scales. In H. I. McCubbin \& A. I. Thompson (Eds.), Family assessment inventories for research and practice (pp. 259-270). Madison: University of Wisconsin.

McGain, B., \& McKinzey, R. K. (1995). The efficacy of group treatment in sexually abused girls. Child Abuse and $\mathrm{Ne}-$ glect, 19, 1157-1169.

Michalski, J. H., Mishna, F., \& Worthington, C. (2003). A multimethod impact evaluation of a therapeutic summer camp program. Child and Adolescent Social Work Journal, 20, 53-76.

Monck, E. (1997). Evaluating therapeutic intervention with sexually abused children. Child Abuse Review, 6, 163-177. 
Nelson-Gardell, D. (1997). Child report of treatment issue resolution: Pilot of a rapid assessment instrument. Child Abuse and Neglect, 21, 309-318.

Nunnally, J. C., \& Bernstein, I. H. (1994). Psychometric theory (3rd ed.). New York: McGraw-Hill.

Oates, R. K., O’Toole, B., Lynch, D. L., Stern, A., \& Cooney, G. (1994). Stability and change in outcomes for sexually abused children. Journal of the American Academy of Child and Adolescent Psychiatry, 33, 945-953.

Ollendick, T.H. (1983). Reliability and validity of the Revised Fear Survey Schedule for Children (FSSC-R). Behaviour Research and Therapy, 21, 685-692.

Ollendick, T. H., Langley, A. K., \& Jones, R. T. (2001). Fear in children and adolescents: Relations with negative life events, attributional style, and avoidant coping. Journal of Child Psychology and Psychiatry, 42, 1029-1034.

Olson, D. H. (1986). Circumplex Model VII: Validation studies and FACES-III. Family Process, 25, 337-350.

Paolucci, E., Genuis, M. L., \& Violato, C. (2001). A metaanalysis of the published research on the effects of child sexual abuse. Journal of Psychology: Interdisciplinary and Applied, 135, 17-36.

Prinstein, M. J., \& La Greca, A. M. (2002). Peer crowd affiliation and internalizing distress in childhood and adolescence: A longitudinal follow-back study. Journal of Research on Adolescence, 12, 325-351.

Reynolds, C. R., \& Richmond, B. O. (1985). Revised Children's Manifest Anxiety Scale manual. Los Angeles: Western Psychological Services.

Spielberger, C. D. (1973). Manual for the State-Trait Anxiety Inventory for Children. Palo Alto, CA: Consulting Psychologists Press.

Storch, E. A., Brassard, M. R., \& Masia-Warner, C. L. (2003). The relationship of peer victimization to social anxiety and loneliness in adolescence. Child Study Journal, 33, 118.

U.S. Department of Health and Human Services. (2003). Child maltreatment 2001: Reports from the states to the $\mathrm{Na}$ tional Child Abuse and Neglect Data System. Washington, DC: U.S. Government Printing Office.

Valle, L. A., \& Silovsky, J. F. (2002). Attributions and adjustment following child sexual and physical abuse. Child Maltreatment, 7, 9-25.

Westenberg, M. P., Drewes, M. J., \& Goedhart, A. W. (2004). A developmental analysis of self-reported fears in late childhood through mid-adolescence: Social-evaluative fears on the rise? Journal of Child Psychology \& Psychiatry, 45, 481-495.
Wolfe, V. V., \& Birt, J. (1995). The psychological sequelae of child sexual abuse. In T. H. Ollendick \& R. J. Prinz (Eds.), Advances in clinical child psychology (pp. 233-263). New York: Plenum.

Wolfe, V. V., Gentile, C., \& Klink, A. (1988). Psychometric properties of the Sexual Abuse Fear Evaluation (SAFE). Unpublished manuscript. London, Canada: University of Western Ontario.

Wolfe, V. V., Gentile, C., Michienzi, T., Sas, L., \& Wolfe, D. A. (1991). The Children's Impact of Traumatic Events Scale: A measure of post-sexual abuse PTSD symptoms. Behavioral Assessment, 13, 359-383.

Wolfe, V. V., Gentile, C., \& Wolfe, D. A. (1989). The impact of sexual abuse on children: A PTSD formulation. $B e^{-}$ havior Therapy, 20, 215-228.

Wolfe, V. V., \& Wolfe, D. A. (1986). The Sexual Abuse Fear Evaluation (SAFE): A subscale for the Fear Survey Schedule for Children-Revised. Unpublished questionnaire. London, Canada: Children's Hospital of Western Ontario.

Genelle K. Sawyer, M.A., is a clinical psychology doctoral student at the University of Nebraska-Lincoln and coordinator for Project SAFE (Sexual Abuse Family Education), a clinical research and treatment program for youth who are sexually abused and their family members who are nonoffending.

Eugenia Hsu Tsao, Ph.D., graduated from the clinical psychology doctoral program at the University of NebraskaLincoln and is currently a child and family psychologist at the UCLA-TIES for Adoption in Los Angeles.

David J. Hansen, Ph.D., is chair and professor of the Psychology Department at the University of NebraskaLincoln, codirector of the Family Interaction Skills Clinic (FISC), and director of Project SAFE (Sexual Abuse Family Education).

Mary Fran Flood, Ph.D., is director of the Psychological Consultation Center (PCC) at the University of Nebras$k a-L i n c o l n$ and codirector of the Family Interaction Skills Clinic (FISC), a specialty clinic of the PCC. She is a pediatric psychologist at Lincoln Medical Education Partnership's Behavioral Health Center. 